\title{
Solubility of Anthracene in Binary Alcohol + Methyl Acetate Solvent Mixtures at $298.2 \mathrm{~K}$
}

\author{
William E. Acree, J r.* \\ Department of Chemistry, University of North Texas, Denton, Texas 76203-5070
}

\begin{abstract}
Experimental solubilities are reported for anthracene dissolved in eight binary alcohol + methyl acetate solvent mixtures at $25^{\circ} \mathrm{C}$. The alcohol cosolvents studied were 1-propanol, 2-propanol, 1-butanol, 2-butanol, 2-methyl-1-propanol, 1-pentanol, 2-pentanol, and 3-methyl-1-butanol. Results of these measurements are used to test two mathematical representations based upon the combined nearly ideal binary solvent (NIBS)/Redlich-Kister and modified Wilson equations. For the eight systems studied, the combined NIBS/ Redlich-Kister equation was found to provide the better mathematical representation of the experimental data, with overall average absolute deviations between measured and calculated values being approximately $\pm 0.5 \%$. Considerably larger deviations were noted in the case of the modified Wilson equation.
\end{abstract}

\section{Introduction}

Solid-liquid equilibrium data of organic nonelectrolyte systems are becoming increasingly important in the petroleum industry, particularly in light of present trends toward heavier feedstocks and the known carcinogenicity/ mutagenicity of many of the larger polycyclic aromatic compounds. Solubility data for a number of polycyclic aromatic hydrocarbons (i.e., anthracene and pyrene) and heteroatom polynuclear aromatics (i.e., carbazole, dibenzothiophene, and xanthene) have been published in the recent chemical literature (for a listing of references, see refs $1-3)$. Despite efforts by experimental ists and scientific organizations, both in terms of new experimental measurements and critically evaluated data compilations, there still exist numerous systems for which solubility data are not readily available.

To address this problem, researchers have turned to predictive methods as a means to generate desired quantities. Numerous equations have been suggested for predicting solute solubilities in binary solvent mixtures. For the most part, the predictive methods do provide fairly reasonable estimates for noncomplexing systems. There still remains, however, the need to develop better predictive expressions and mixing models to describe the more nonideal complexing systems bel ieved to contain hydrogen bonding solvent components. Continued development of solution models for describing the thermodynamic properties of a solute in binary solvent systems requires that a large database be available for assessing the applications and limitations of derived expressions. Currently, only a limited database exists for crystalline nonel ectrolyte solubility in binary solvent mixtures. For this reason, anthracene solubilities were determined in eight binary alcohol + methyl acetate solvent mixtures. Results of these measurements are used to further test the descriptive abilities of two previously derived expressions.

\section{Experimental Methods}

Anthracene (Aldrich, 99\%) was recrystallized threetimes from acetone. 1-Propanol (Aldrich, 99+\%, anhydrous), 2-propanol (Aldrich, 99+\%, anhydrous), 1-butanol (Aldrich,

\footnotetext{
* To whom correspondence should be addressed. E-mail: acree@unt.edu.
}

99.8+\%), 2-butanol (Aldrich, 99+\%, anhydrous), 2-methyl1-propanol (Aldrich, 99+\%, anhydrous), 1-pentanol (Aldrich 99+\%), 2-pentanol (Acros, 99+\%), 3-methyl-1-butanol (Aldrich 99+\%, anhydrous), and methyl acetate (Aldrich, $99.5 \%$, anhydrous) were stored over molecular sieves and distilled shortly before use. Gas chromatographic analysis showed solvent purities to be $99.7 \mathrm{~mol} \%$ or better. Binary solvent mixtures were prepared by mass so that compositions could be calculated to 0.0001 mole fraction.

Excess solute and solvent were placed in amber glass bottles and allowed to equilibrate in a constant temperature water bath at $(25.0 \pm 0.1){ }^{\circ} \mathrm{C}$ with periodic agitation for at least 3 days (often longer). Attainment of equilibrium was verified both by repetitive measurements after a minimum of 3 additional days and by approaching equilibrium from supersaturation by pre-equilibrating the solutions at a higher temperature. Aliquots of saturated anthracene solutions were transferred through a coarse filter into a tared vol umetric flask to determine the amount of sample and diluted quantitatively with methanol for spectrophotometric analysis at $356 \mathrm{~nm}$ on a Bausch and Lomb Spectronic 2000. Concentrations of the dilute solutions were determined from a Beer-Lambert law absorbance versus concentration working curve derived from measured absorbances of standard solutions of known molar concentrations. Apparent molar absorptivities of the nine standard solutions varied systematically with molar concentration and ranged from approximately $\in /\left(\mathrm{L} \mathrm{mol}^{-1}\right.$ $\left.\mathrm{cm}^{-1}\right)=7450$ to $\in /\left(\mathrm{L} \mathrm{mol}^{-1} \mathrm{~cm}^{-1}\right)=7150$ for anthracene concentrations ranging from $\mathrm{C} /\left(\mathrm{mol} \mathrm{L}^{-1}\right)=6.75 \times 10^{-5}$ to $\mathrm{C} /\left(\mathrm{mol} \mathrm{L}^{-1}\right)=2.25 \times 10^{-4}$. I dentical molar absorptivities were obtained for select anthracene standard solutions that contained up to $5 \mathrm{vol} \%$ of the neat alcohol and methyl acetate cosolvents. Experimental anthracene solubilities in the eight binary alcohol + methyl acetate solvent mixtures are listed in Table 1. Numerical values represent the average of between four and eight independent determinations, with the measured values being reproducible to within $\pm 1.0 \%$.

\section{Results and Discussion}

Acree and co-workers ${ }^{4-6}$ suggested possible mathematical representations for isothermal solubility data based 
Table 1. Experimental Mole Fraction Solubilities of Anthracene $\left(X_{A}^{\text {sat }}\right)$ in Binary Alcohol (B) + Methyl Acetate (C) Solvent Mixtures at $25.0^{\circ} \mathrm{C}$

\begin{tabular}{|c|c|c|c|}
\hline$x_{C}^{\circ}$ & $x_{A}^{\text {sat }}$ & $x_{C}^{\circ}$ & $x_{A}^{\text {sat }}$ \\
\hline \multicolumn{4}{|c|}{ 1-Propanol (B) + Methyl Acetate (C) } \\
\hline 0.0000 & 0.000591 & 0.5952 & 0.00274 \\
\hline 0.1001 & 0.000913 & 0.7889 & 0.00328 \\
\hline 0.1904 & 0.001230 & 0.8805 & 0.00349 \\
\hline 0.3882 & 0.001946 & 1.0000 & 0.00364 \\
\hline 0.4908 & 0.00235 & & \\
\hline \multicolumn{4}{|c|}{ 2-Propanol (B) + Methyl Acetate (C) } \\
\hline 0.0000 & 0.000411 & 0.5987 & 0.00247 \\
\hline 0.1177 & 0.000735 & 0.7864 & 0.00311 \\
\hline 0.1959 & 0.001006 & 0.8821 & 0.00334 \\
\hline 0.3782 & 0.001634 & 1.0000 & 0.00364 \\
\hline 0.4887 & 0.00206 & & \\
\hline \multicolumn{4}{|c|}{ 1-Butanol (B) + Methyl Acetate (C) } \\
\hline 0.0000 & 0.000801 & 0.6378 & 0.00303 \\
\hline 0.1390 & 0.001260 & 0.8238 & 0.00350 \\
\hline 0.2247 & 0.001571 & 0.9075 & 0.00361 \\
\hline 0.4285 & 0.00236 & 1.0000 & 0.00364 \\
\hline 0.5350 & 0.00270 & & \\
\hline \multicolumn{4}{|c|}{ 2-Butanol (B) + Methyl Acetate (C) } \\
\hline 0.0000 & 0.000585 & 0.6377 & 0.00296 \\
\hline 0.1246 & 0.001017 & 0.8250 & 0.00347 \\
\hline 0.2150 & 0.001375 & 0.9088 & 0.00359 \\
\hline 0.4262 & 0.00217 & 1.0000 & 0.00364 \\
\hline 0.5440 & 0.00264 & & \\
\hline \multicolumn{4}{|c|}{ 2-Methyl-1-propanol (B) + M ethyl Acetate (C) } \\
\hline 0.0000 & 0.000470 & 0.6429 & 0.00283 \\
\hline 0.1192 & 0.000832 & 0.8241 & 0.00341 \\
\hline 0.2371 & 0.001249 & 0.9120 & 0.00357 \\
\hline 0.4358 & 0.00203 & 1.0000 & 0.00364 \\
\hline 0.5342 & 0.00239 & & \\
\hline \multicolumn{4}{|c|}{ 1-Pentanol (B) + Methyl Acetate (C) } \\
\hline 0.0000 & 0.001097 & 0.6673 & 0.00357 \\
\hline 0.1302 & 0.001630 & 0.8454 & 0.00374 \\
\hline 0.2612 & 0.00217 & 0.9195 & 0.00370 \\
\hline 0.4757 & 0.00301 & 1.0000 & 0.00364 \\
\hline 0.5814 & 0.00337 & & \\
\hline \multicolumn{4}{|c|}{ 2-Pentanol (B) + Methyl Acetate (C) } \\
\hline 0.0000 & 0.000800 & 0.6746 & 0.00329 \\
\hline 0.1349 & 0.001320 & 0.8480 & 0.00361 \\
\hline 0.2576 & 0.001821 & 0.9202 & 0.00365 \\
\hline 0.4706 & 0.00262 & 1.0000 & 0.00364 \\
\hline 0.5936 & 0.00308 & & \\
\hline \multicolumn{4}{|c|}{ 3-Methyl-1-butanol (B) + Methyl Acetate (C) } \\
\hline 0.0000 & 0.000727 & 0.6787 & 0.00319 \\
\hline 0.1474 & 0.001214 & 0.8531 & 0.00350 \\
\hline 0.2682 & 0.001677 & 0.9412 & 0.00360 \\
\hline 0.4899 & 0.00260 & 1.0000 & 0.00364 \\
\hline 0.5722 & 0.00287 & & \\
\hline
\end{tabular}

upon either a combined NIBS/Redlich-Kister model

$$
\ln x_{A}^{\text {sat }}=x_{B}^{o} \ln \left(x_{A}^{\text {sat }}\right)_{B}+x_{C}^{o} \ln \left(x_{A}^{\text {sat }}\right)_{C}+x_{B}^{o} x_{C}^{\circ} \sum_{i=0}^{N} S_{i}\left(x_{B}^{o}-x_{C}^{o}\right)^{i}
$$

or a modified Wilson equation

$$
\begin{aligned}
\ln \left[\mathrm{a}_{A}(\mathrm{~s}) / \mathrm{x}_{A}^{\mathrm{sat}}\right] & =1-\mathrm{x}_{B}^{\circ}\left\{1-\ln \left[\mathrm{a}_{A}(\mathrm{~s}) /\left(\mathrm{x}_{A}^{\mathrm{sat}}\right)_{B}\right]\right\} /\left(\mathrm{x}_{B}^{\circ}+\right. \\
\left.\mathrm{x}_{C}^{\circ} \Lambda_{B C}^{\mathrm{adj}}\right) & -\mathrm{x}_{C}^{\circ}\left\{1-\ln \left[\mathrm{a}_{\mathrm{A}}(\mathrm{s}) /\left(\mathrm{x}_{A}^{\mathrm{sat}}\right)_{C}\right]\right\} /\left(\mathrm{x}_{B}^{\circ} \Lambda_{C B}^{\mathrm{adj}}+\mathrm{x}_{C}^{\circ}\right)
\end{aligned}
$$

where the various $S_{i}$ and $\Lambda_{i j}^{\text {adj }}$ "curve-fit" parameters can be evaluated via least-squares analysis. In eqs 1 and $2 x_{B}^{\circ}$ and $x_{C}^{\circ}$ refer to the initial mole fraction composition of the binary solvent calculated as if solute (A) were not present, $a_{A}(s)$ is the activity of the solid solute, $N$ is the number of curve-fit parameters used, and $\left(x_{A}^{\text {sat }}\right)_{i}$ is the saturated mole fraction solubility of the solute in pure solvent $\mathrm{i}$.
The combined NIBS/Redlich-Kister and modified Wilson equations have been shown to provide very accurate mathematical representations of anthracene, pyrene, and carbazole solubilities in a large number of both complexing and noncomplexing solvent mixtures. ${ }^{1-3} \mathrm{~J}$ ouyban-Gharamaleki and co-workers ${ }^{7-10}$ successfully used the volume fraction, $\phi_{\mathrm{i}}$, modification of eq 1

$\ln x_{A}^{\text {sat }}=\phi_{B}^{\circ} \ln \left(x_{A}^{\text {sat }}\right)_{B}+\phi_{C}^{\circ} \ln \left(x_{A}^{\text {sat }}\right)_{C}+\phi_{B}^{\circ} \phi_{C}^{\circ} \sum_{i=0}^{N} S_{i}\left(\phi_{B}^{\circ}-\phi_{C}^{\circ}\right)^{i}$

to describethe solubility behavior of various drug molecules in binary aqueous-organic solvent mixtures. In the pharmaceutical industry, researchers often express the solvent composition in terms of volume fractions, rather than in terms of mole fractions. In the case of structurally similar drug molecules, the numerical values of the $S_{i}$ coefficients were found to be nearly constant in a given binary solvent mixture. ${ }^{10}$ More recently, Deng et al. ${ }^{11-13}$ and Pribyla et al. ${ }^{14-16}$ have shown that the $S_{i}$ coefficients determined by regressing experimental anthracene data in binary alkane + alkane, alkane + alcohol, alcohol + alcohol, alcohol + ether, and alkane + ether solvent mixtures allows one to predict anthracene solubilities in ternary al kane + al kane + alcohol, alkane + alcohol + alcohol, and alkane + alcohol + ether solvent mixtures. The predictive expression for the ternary solvent mixture is

$$
\begin{array}{r}
\ln x_{A}^{\text {sat }}=x_{B}^{o} \ln \left(x_{A}^{s a t}\right)_{B}+x_{C}^{o} \ln \left(x_{A}^{s a t}\right)_{C}+x_{D}^{\circ} \ln \left(x_{A}^{s a t}\right)_{D}+ \\
x_{B}^{\circ} x_{C}^{\circ} \sum_{i=0}^{r} S_{i, B C}\left(x_{B}^{\circ}-x_{C}^{\circ}\right)^{i}+x_{B}^{\circ} x_{D}^{\circ} \sum_{j=0}^{s} S_{j, B D}\left(x_{B}^{\circ}-x_{D}^{\circ}\right)^{j}+ \\
x_{C}^{\circ} x_{D}^{\circ} \sum_{k=0}^{t} S_{k, C D}\left(x_{C}^{\circ}-x_{D}^{\circ}\right)^{k}
\end{array}
$$

a mole fraction average of the logarithmic solute solubilities in the three pure solvents $\left[\left(x_{A}^{\text {sat }}\right)_{B},\left(x_{A}^{\text {sat }}\right)_{C}\right.$, and $\left.\left(x_{A}^{\text {sat }}\right)_{D}\right]$ plus a Redlich-Kister summation term for each solvent pair. The documented success ${ }^{11-16}$ of eq 4 in predicting anthracene solubilities in more than 60 different ternary solvent systems illustrates the need for measured solute solubilities in binary solvent mixtures.

The ability of eqs 1 and 2 to mathematically represent the experimental solubility of anthracene in the eight binary alcohol + methyl acetate mixtures is summarized in Table 2 in the form of "curve-fit" parameters and percent deviations in back-calculated solubilities. The numerical value of $a_{A}(s)$ used in the modified Wilson computations was $a_{A}(s)=0.00984 .{ }^{17}$ Each percent deviation is based upon the measured anthracene solubility data at the seven different binary solvent compositions. Careful examination of Table 2 reveals that both equations provided a fairly accurate mathematical representation for how the solubility of anthracene varies with solvent composition. For the eight anthracene systems studied, eq 1 was found to provide the better mathematical representation of the experimental data. Deviations between the experimental mole fraction solubilities and back-calculated values based upon eq 1 differed by an overall average absolute deviation of about $\pm 0.5 \%$, which is less than the experimental uncertainty.

Considerably larger deviations were noted in the case of eq 2. The failure of eq 2 to adequately describe the measured anthracene solubility data was initially unexpected in that the equation has been used successfully in numerous earlier studies. ${ }^{1-3}$ In examining the actual mole 
Table 2. Mathematical Representation of Anthracene Solubilities in Several Binary Alcohol (B) + Methyl Acetate (C) Solvent Mixtures

\begin{tabular}{|c|c|c|c|c|}
\hline \multirow{2}{*}{$\begin{array}{c}\text { binary solvent system } \\
\text { component } \mathrm{B}+\text { component } \mathrm{C}\end{array}$} & \multicolumn{2}{|c|}{ eq 1} & \multicolumn{2}{|c|}{ eq 2} \\
\hline & $\mathrm{Si}^{\mathrm{a}}$ & $\%$ dev $^{b}$ & $\Lambda_{\mathrm{ij}}^{\mathrm{adj} \mathrm{c}}$ & $\% \operatorname{dev}^{b}$ \\
\hline 1-propanol + methyl acetate & $\begin{array}{l}1.939 \\
0.691 \\
0.453\end{array}$ & 0.6 & $\begin{array}{l}3.000 \\
0.303\end{array}$ & 2.9 \\
\hline 2-propanol + methyl acetate & $\begin{array}{l}2.177 \\
0.947 \\
0.418\end{array}$ & 0.7 & $\begin{array}{l}2.870 \\
0.564\end{array}$ & 1.6 \\
\hline 1-butanol + methyl acetate & $\begin{array}{l}1.673 \\
0.328 \\
0.230\end{array}$ & 0.3 & $\begin{array}{l}3.330 \\
0.245\end{array}$ & 4.1 \\
\hline 2-butanol + methyl acetate & $\begin{array}{l}2.106 \\
0.744 \\
0.564\end{array}$ & 0.5 & $\begin{array}{l}3.390 \\
0.216\end{array}$ & 3.8 \\
\hline $\begin{array}{l}\text { 2-methyl-1-propanol + methyl } \\
\text { acetate }\end{array}$ & $\begin{array}{l}2.211 \\
0.714 \\
0.587\end{array}$ & 0.4 & $\begin{array}{l}3.220 \\
0.216\end{array}$ & 3.7 \\
\hline 1-pentanol + methyl acetate & $\begin{array}{l}1.775 \\
0.330 \\
0.120\end{array}$ & 0.6 & $\begin{array}{l}4.200 \\
0.274\end{array}$ & 6.5 \\
\hline 2-pentanol + methyl acetate & $\begin{array}{l}1.916 \\
0.558 \\
0.375\end{array}$ & 0.4 & $\begin{array}{l}3.700 \\
0.274\end{array}$ & 5.0 \\
\hline $\begin{array}{l}\text { 3-methyl-1-butanol + methyl } \\
\text { acetate }\end{array}$ & $\begin{array}{r}1.915 \\
0.417 \\
-0.076\end{array}$ & 0.3 & $\begin{array}{l}3.580 \\
0.274\end{array}$ & 5.1 \\
\hline
\end{tabular}

a Combined NIBS/Redlich-Kister curve-fit parameters are ordered as $\mathrm{S}_{0}, \mathrm{~S}_{1}$, and $\mathrm{S}_{2} \cdot{ }^{\mathrm{b}}$ Deviation $(\%)=(100 / \mathrm{N}) \sum \mid\left[\left(\mathrm{C}_{\mathrm{A}}^{\text {sat }}\right)^{\text {calc }}-\right.$ $\left.\left(x_{A}^{\text {sat }}\right)^{\exp }\right] /\left(x_{A}^{\text {sat }}\right)^{\exp } \mid{ }^{\circ}{ }^{c}$ Adjustable parameters for the modified Wilson equation are ordered as $\Lambda_{B C}^{\text {adj }}$ and $\Lambda_{C B}^{\text {adj }}$.

fraction solubilities, it was noted that the $x_{C}^{\circ}\left\{1-\ln \left[a_{A}\right.\right.$ $\left.\left.(\mathrm{s}) /\left(\mathrm{x}_{\mathrm{A}}^{\mathrm{sat}}\right)_{C}\right]\right\} /\left(\mathrm{x}_{\mathrm{B}}^{\circ} \Lambda_{\mathrm{CB}}^{\mathrm{adj}}+\mathrm{x}_{\mathrm{C}}^{\circ}\right)$ term contributes very little to the overall solubility prediction for these particular eight systems. The numerical value of $1-\ln \left[a_{A}(s) /\left(x_{A}^{s a t}\right)_{C}\right]$ is approximately 0.0052532 , and as a result eq 2 reduces to essentially a one-parameter mathematical representation. The loss of descriptive accuracy is not too surprising given this fact. In general, the descriptive accuracy of any mathematical representation improves with increasing number of "curve-fit" parameters.

\section{Literature Cited}

(1) Acree, W. E., J r. Polycyclic Aromatic Hydrocarbons in Pure and Binary Solvents; IUPAC Solubility Data Series, Vol. 54; Oxford University Press: Oxford, U.K., 1994.

(2) Acree, W. E., J r. Polycyclic Aromatic Hydrocarbons: Binary Nonaqueous Systems: Part 1 (Solutes A-E); IUPAC Solubility Data Series, Vol. 58; Oxford University Press: Oxford, U.K., 1995.
(3) Acree, W. E., J r. Polycyclic Aromatic Hydrocarbons: Binary Nonaqueous Systems: Part 2 (Solutes F-Z); IUPAC Solubility Data Series, Vol. 59; Oxford University Press: Oxford, U.K., 1995.

(4) Acree, W. E., J r. Mathematical Representation of Thermodynamic Properties. Part 2. Derivation of the Combined Nearly Ideal Binary Solvent (NIBS)/Redlich-Kister Mathematical Representation from a Two-Body and Three-Body Interactional Mixing Model. Thermochim. Acta 1992, 198, 71-79.

(5) Acree, W. E., J r.; McCargar, J . W.; Zvaigzne, A. I.; Teng, I.-L. Mathematical Representation of Thermodynamic Properties. Carbazole Solubilities in Binary Alkane + Dibutyl Ether and Alkane + Tetrahydropyran Solvent Mixtures. Phys. Chem. Liq. 1991, 23, 27-35.

(6) Acree, W. E., J r.; Zvaigzne, A. I. Thermodynamic Properties of Nonelectrolyte Solutions. Part 4. Estimation and Mathematical Representation of Solute Activity Coefficients and Solubilities in Binary Solvents Using the NIBS and Modified Wilson Equation. Thermochim. Acta 1991, 178, 151-167.

(7) J ouyban-Gharamaleki, A.; Clark, B.J .; Acree, W. E., J r. Prediction of Drug Solubility in Ternary Solvent Mixture. Drug Dev. Ind. Pharm. 2000, 26, 971-973.

(8) J ouyban-Gharamaleki, A.; Acree, W. E.,J r. Comparison of Models for Describing Multiple Peaks in Solubility Profiles. Int. J . Pharm. 1998, 167, 177-182.

(9) J ouyban-Gharamaleki, A.; Hanaee, J . A Novel Method for Improvement of the CNIBS/R-K Equation. Int. J . Pharm. 1997, 154, 243-245.

(10) J ouyban-Gharamaleki, A.; Barzegar-J alali, M.; Acree, W. E., J r. Solubility Correlation of Structurally Related Drugs in Binary Solvent Mixtures. Int. J . Pharm. 1998, 166, 205-209.

(11) Deng, T.; Childress, S. D.; De Fina, K. M.; Sharp, T. L.; Acree, W. E., J r. Solubility of Anthracene in Ternary Propanol + Butanol $+2,2,4$-Trimethylpentane Solvent Mixtures. J . Chem. Eng. Data 1998, 43, 1065-1067.

(12) Deng, T.; Childress, S. D.; De Fina, K. M.; Acree, W. E., J r. Solubility of Anthracene in Ternary Propanol + Butanol + Heptane Solvent Mixtures. Chem. Eng. Commun. 1999, 172, $217-$ 224.

(13) Deng, T. Thermodynamic Properties of Nonelectrolyte Solutes in Ternary Solvent Mixtures. Ph.D. Dissertation, University of North Texas, 1999.

(14) Pribyla, K. J .; Ezell, C.; Van, T. T.; Acree, W. E.,J r. Solubility of Anthracene in Ternary Methyl tert-Butyl Ether + Alcohol + 2,2,4Trimethylpentane Solvent Mixtures at $298.15 \mathrm{~K}$. J . Chem. Eng. Data 2000, 45, 974-976.

(15) Pribyla, K.J .; Chuca, I.; Van, T. T.; Acree, W. E., J r. Solubility of Anthracene in Ternary Methyl tert-Butyl Ether + Alcohol + Heptane Solvent Mixtures at 298.15 K. J . Chem. Eng. Data 2000, 45, 533-535.

(16) Pribyla, K. J. Thermochemical Study of Crystalline Solutes Dissolved in Ternary Hydrogen-Bonding Solvent Mixtures. Ph.D. Dissertation, University of N orth Texas, 2001.

(17) Powell, J. R.; Coym, K. S.; Acree, W. E., J r. Solubility of Anthracene in Binary Alcohol + 2-Methoxyethyl Ether Solvent Mixtures. J. Chem. Eng. Data 1997, 42, 395-397.

Received for review February 20, 2001. Accepted April 4, 2001.

J E0100591 